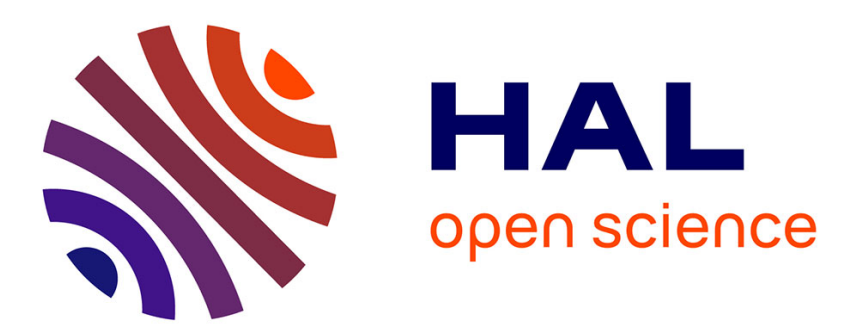

\title{
Distribution Grid Services and Flexibility Provision by Electric Vehicles: a Review of Options
}

\author{
Katarina Knezovic, Mattia Marinelli, Yannick Perez, Paul Codani
}

\section{To cite this version:}

Katarina Knezovic, Mattia Marinelli, Yannick Perez, Paul Codani. Distribution Grid Services and Flexibility Provision by Electric Vehicles: a Review of Options. Power Engineering Conference (UPEC), 2015 50th International Universities, Sep 2015, Stoke on Trent United Kingdom. pp.16, 10.1109/UPEC.2015.7339931 . hal-01266937

\section{HAL Id: hal-01266937 \\ https://hal-centralesupelec.archives-ouvertes.fr/hal-01266937}

Submitted on 4 Feb 2016

HAL is a multi-disciplinary open access archive for the deposit and dissemination of scientific research documents, whether they are published or not. The documents may come from teaching and research institutions in France or abroad, or from public or private research centers.
L'archive ouverte pluridisciplinaire HAL, est destinée au dépôt et à la diffusion de documents scientifiques de niveau recherche, publiés ou non, émanant des établissements d'enseignement et de recherche français ou étrangers, des laboratoires publics ou privés. 


\section{Distribution Grid Services and Flexibility Provision by Electric Vehicles: a Review of Options}

\author{
Katarina Knezović \\ Mattia Marinelli \\ Center for Electric Power and Energy (CEE) \\ Ris $\varnothing$ Campus, Technical University of Denmark \\ 4000 Roskilde, Denmark \\ email: kknez@elektro.dtu.dk
}

\author{
Paul Codani \\ Yannick Perez \\ Group of Electrical Engineering Paris (GEEPS) \\ UMR CNRS 8507, CentraleSupelec, UPSud, UPMC \\ 91190 Gif-sur-Yvette, France \\ email: paul.codani@centralesupelec.fr
}

\begin{abstract}
Due to the increasing penetration of distributed generation and new high-power consumption loads - such as electric vehicles (EVs) - distribution system operators (DSO) are facing new grid security challenges. DSOs have historically dealt with such issues by making investments in grid reinforcement. However, an alternative solution, enabled by the expected roll-out of smart meters and high penetration of flexible loads, would be the increased use of flexibility services. Flexible loads, with EVs at their forefront, can modulate their consumption or even inject power back to the grid depending on current grid conditions. In return, flexibility provision should be remunerated accordingly. In this paper, the authors are interested in making an accurate description of the flexibility services at the distribution level which could be provided by EVs as well as their requirements, e.g. location, activation time and duration. Market design recommendations for enhancing the provision of DSO grid services by EVs are derived from the conducted analysis.

Index Terms-Distribution network, electric vehicles, flexibility services, market design, regulation.
\end{abstract}

\section{INTRODUCTION}

Historically, electric grids used to be vertically integrated with large power plants producing electricity for end-users, and single-direction electricity flowing from production units through the transmission and distribution grids to the consumers. In this context, Distribution System Operators (DSOs) have traditionally dealt with grid security issues by using planning and network development methods [1]. However, the security of DSO grid operations is nowadays threatened by the penetration of distributed generation (DG) units and electric vehicles (EVs), which impose new constraints such as bi-directional flows, high power during peak periods and unpredictability [2]. If not managed properly, these constraints could result in over-investments and additional energy losses [3].

Apart from traditional grid reinforcement strategies, using flexible resources could be a mean to deal with these arising issues [4]. In particular, EVs could be valuable flexibility service providers [5]-[7] since their charging rate is controllable within a very short response time, they can potentially inject power back to the grid via Vehicle-to-Grid (V2G) technology, and they are typically plugged in most of the day [8].
However, clear stakeholder roles, responsibilities and market design rules for allowing these flexibility resources to be managed efficiently still need to be defined. The issue of defining suitable and proper market rules for demand response participation has been highlighted for TSO services [9]-[11], but much less tackled for DSO services. In this paper, the authors aim at deducing the technical requirements as well as the organizational framework for the provision of DSO flexibility services by EVs through the literature survey of papers and reports focusing on the flexibility at the distribution level. Market design recommendations are derived from the findings of this survey. The authors focus specifically on EVs as distributed flexibility sources since they have promising characteristics compared to other sources: high power, good availability and predictability, and easy controllability. However, the approach and the results could be extended to other types of flexibility resources such as electric heating systems, water heaters and similar.

The paper is organized as follows. In Section II, the way DSOs have been operating their networks for the past decades is recalled. Then, Section III provides the literature review of previous work dealing with the provision of flexibility services by EVs, from which we deduce market design recommendations presented in Section IV. Finally, Section $\mathrm{V}$ presents the conclusion.

\section{HistoriCAL GRID OPERATION BY DSOS}

The distribution sector is characterized by high diversity of DSOs, both in the number which varies from country to country, as well as in the magnitude of corresponding control areas. Some DSOs operate large sets of distribution networks over large regions while others operate a limited amount of MV feeders. Table I summarizes the number of DSOs for several European countries - including Denmark, Italy and France - in order to provide a brief overview of the current system complexity. No matter where, all DSOs have historically operated grids with radial topologies, from HV/MV substations to the end-users. Electricity flow was unidirectional only, and consumption loads were largely inflexible. In this context, DSO activities were mainly focused 
TABLE I

Active DSOS In SELECTED EuRopean Countries, ADAPTED FROM [12], [13]

\begin{tabular}{cccc}
\hline Country & Total DSOs & $\begin{array}{c}\text { DSOs with under } \\
\mathbf{1 0 0 0 0 0} \text { customers }\end{array}$ & $\begin{array}{c}\text { Dominant DSO } \\
\text { (>80\% of } \\
\text { distributed power) }\end{array}$ \\
\hline Denmark & 76 & 68 & $\mathrm{n} / \mathrm{a}$ \\
\hline France & 148 & 143 & ERDF \\
\hline Germany & 883 & 780 & $\mathrm{n} / \mathrm{a}$ \\
\hline Italy & 151 & 124 & ENEL Distribuzione \\
\hline Ireland & 1 & 0 & ESB Networks \\
\hline \hline
\end{tabular}

on long term grid planning and design rather than on real-time operation.

As a matter of fact, utilities address two main concerns, i.e. voltage and congestion issues, by investing in grid reinforcement in a rather passive way. Congestion is dealt with by upgrading the cables/transformers to equivalent components with higher rated power $(70 \%$ capacity limit is used as a "rule-of-thumb" since remaining $30 \%$ is saved for supplying neighbouring feeders in case of fault [14]). Voltage regulation is mainly performed with the addition of capacitor banks, or by means of transformers with automatically adjusting taps [15] since according to European standard EN50160, the 10 minutes voltage deviation should not exceed $\pm 10 \% U_{n}$ on a weekly basis [16]. In addition, some countries have already proposed stricter voltage requirements, e.g. Germany is considering lowering the band to $\pm 4 \% U_{n}$ [17].

Moreover, DSOs remuneration scheme is most of the time based on a cost of service method, meaning that the remuneration is based on an estimation of their costs, tightly linked to their investment plans [1]. Thus, DSOs have a strong incentive in promoting their investments to solve their management issues. Considering the current funding methods, and even though quality of service indicators are sometimes included in the remuneration calculation, it is more attractive for the DSOs to conduct grid reinforcement work than to implement active demand management strategies. We will call this historical DSO methodology as "investment programs to fit and forget". In this approach, the value of flexibility is non-existent.

On the other hand, with the liberalization of the electricity industry and the recent technological improvements, all stakeholders' roles are evolving and more active management could be introduced in the electricity industry, which is particularly true for DSOs. This new methodology of investments, management and remuneration of decentralized flexibility resources will be called "proactive DSO".

Indeed, where the production, the transportation and the distribution used to be bundled, most of the European countries have now more or less unbundled those activities depending on the national institutional and industrial contexts [1]. Moreover, the traditional system operation is challenged by the introduction of new units, such as distributed renewable resources and EVs. The latter represent a high load compared to the household consumption and should not be considered only as passive assets. Proper coordination and activation can provide more flexibility, which can enhance both efficiency and the reliability of the distribution system. The roll-out of smart meters may provide DSOs with the ability to forecast, monitor and control distributed unit behaviors more accurately than they used to, thus allowing them to change their activities from ex-post corrective activities to performing proactive grid management, if the remuneration scheme and the building of appropriate competencies are performed.

However, this change would require regulation evolutions as highlighted by the THINK project [18]. We want to stress the fact that the development of ICT and smart grid is not fostered by the current remuneration schemes. In order to promote them, flexibility contracting and procurement either on bilateral basis or through a clearing house are required.

In the rest of the paper, the authors aim at characterizing the required future DSO market design for flexibility procurement.

\section{Flexibility Provision by Electric Vehicles}

\section{A. General considerations about flexibility services}

In this section, the authors are concerned with showing how EVs could be efficient flexibility providers for both voltage control and congestion issues, which are the two main problems arising with the penetration of new units, and under which conditions. In the following subsections, literature review focusing on projects and research papers demonstrating the value of EV flexibility for voltage and congestion control is conducted. Voltage regulation is of paramount importance. Among others, under- and over-voltages can cause [15]:

- equipment dysfunctions or failure due to operation out of the rated ranges;

- tripping of sensitive loads;

- overloading of induction motors;

- higher no-load losses in transformers.

Therefore, the cost of voltage regulation to society amounts to significant values. Voltage could be controlled through the modulation of active and reactive power of end-user flexible loads to comply with the standard.

Transformers, underground and overhead lines are manufactured to operate at a given rated power or current (ampacity). Overloading will inevitably result in overheating temperatures, and thus in shortened life expectancies for the mentioned components. Reducing the transformer and cable lifetime can significantly increase the grid operating costs. Table II provides orders of magnitude for cost estimations of the main distribution grid components: underground cables, overhead lines and transformer substations. HV, MV and LV respectively stand for High Voltage Medium Voltage and Low Voltage, while PM and GM stand respectively for Pole Mounted and Ground Mounted.

Active power consumed by flexible loads could be modulated as an effective way to mitigate congestion and overloading. For instance, reference [4] finds out that a flexibility product of $100-200 \mathrm{~kW}$ that would be called for 
TABLE II

Assets COST, ADAPTED FROM [2], [3]

\begin{tabular}{cc}
\hline \hline Component & Estimated cost \\
\hline MV lines/cables & $100-200 \mathrm{k} € / \mathrm{km}$ \\
\hline LV cables & $70-100 \mathrm{k} € / \mathrm{km}$ \\
\hline LV lines & $30-65 \mathrm{k} € / \mathrm{km}$ \\
\hline GM MV/LV transformer & $14-35 \mathrm{k} €$ \\
\hline PM MV/LV transformer & $5 \mathrm{k} €$ \\
\hline HV/MV transformer & $1700-5200 \mathrm{k} €$ \\
\hline \hline
\end{tabular}

a duration of $1-4$ hours once a year would be worth 7500 $€ /$ year.

Further subsections present literature review on flexibility provision by EVs, i.e. congestion management in III-B and voltage regulation in III-C.

\section{B. Local congestion issues}

In [19], the authors are concerned with the supervision of the overloading occurrences of an eco-district transformer. First, an optimal sizing of the substation transformer is proposed, considering only commercial and residential consumptions. Then, EVs and PV panels are introduced in the district, triggering major transformer overloading periods. Finally, with the implementation of an Energy Management System using EVs as flexible resources, the authors show significant improvements in transformer operating conditions: the average overloading power is reduced by $71 \%$ and the yearly electricity costs by $17 \%$. This work considers a centralized approach with an aggregator which is responsible for dispatching the required power flow among the EVs with V2G capability, depending on the transformer conditions, at 10 minutes basis. It is assumed that EV users provide the aggregator with their future needs for transportation. The location of the EVs in the district (i.e. to which node there are plugged-in) is of little importance.

Reference [20] proposes an algorithm for global system operation where EVs modify their charging pattern to alleviate network congestions. The algorithm was tested on a microgrid with three different EV patterns. In every case, a small contribution from EVs mitigates the congestion problems. However, if the congestion problem is too high, the change in reactive power is needed since modulating the active power is not enough to reduce the apparent power.

Congestion management based on direct control and price-based coordination is discussed in [7]. A market framework, which can minimize the charging cost while respecting the hard constraints imposed by the EV owners and DSOs, is proposed. The algorithm is tested on a $10 \mathrm{kV}$ radial grid with 1400 households on 15 minutes values showing that EVs reschedule the charging to the lower-price period in order to avoid congestions. However, additional coordination is needed since all EVs react to the same shadow price signal and can therefore cause new congestion. This is easily solved by limiting the number of EVs which respond to the price signal. Since this framework is based on linear programming methodology for modelling the EV charging process, it is flexible and scalable for diverse control schemes.

\section{Voltage control issues}

In reference [21], the authors suggest a decentralized approach to provide voltage regulation with electric vehicles, both using active and reactive power control with unidirectional power flows. A central aggregator gathers all the voltage values for all the network nodes, and communicates these data to all EVs which then adjust their charging rates accordingly. The EV decision can be either global (taking into account all the network nodes) or local (considering only the neighbour nodes). The simulation time step is 30 minutes, and each EV is located at a precise network node. The method employed provides fair results; however, a comparison with a simple droop-controller method is conducted and the results from the proposed strategy barely outweigh those achieved with the droop-controller.

Reference [22] also tackles the issue of voltage control, but with 11kWh Plug-in Hybrid Vehicles (PHEVs). As in the previous reference, an IEEE node test feeder and load-flow equations are used to compute the voltage in each node of the network - thus the location of the EVs is determinant. Bidirectional $4 \mathrm{~kW}$ charging stations are available for all EVs, which control their charging/discharging power in response to a charging cost-minimization problem. Voltage deviation limitations are expressed in the constraints of the optimization algorithm. It is noticeable that the EV only takes into account the voltage at the node it is plugged in; thus, an embedded controller could be responsible for designing the entire command - no need for a third party sending control commands over. As a matter of fact, the authors argue that such a controller could be embedded in the EV charger. A comparison is conducted between uncoordinated and coordinated charging scenarios; the percentage of excessive voltage deviations is reduced to zero for a PHEV penetration rate of $30 \%$ under the coordinated scenario.

Decentralized approach of active power modulation based on voltage droop control is presented in [23]. The impact of such a controller is simulated for different scenarios differing in EV charging simultaneity and charging duration. The analysis shows that voltage droop eliminates EV-induced voltage magnitudes below 0.85 p.u. and reduces the voltage unbalance factor. Droop parameters can also be optimized to support other objectives such as decreasing the grid losses.

In order not to modulate active power and consequently affect user comfort, decentralized voltage regulation can be done only by the means of reactive power control as shown in [5] and [6]. In addition, this leaves the possibility of using the active power for other services if the user agrees, e.g. frequency regulation [24]. When controlling the voltage by reactive power, one has to address the additional losses caused by increased currents. In [6], the authors show that voltage benefits are greater than the increased loading drawbacks. More precisely, relative voltage increase is up to $2.5 \%$ while the losses are not notably increased. Moreover, in one of the 
cases, the reactive power control is even needed to maintain the voltages within the technical limits while the losses are decreased due to compensation of already present inductive reactive power.

\section{MARKet Design Recommendations}

\section{A. Technical requirements for efficient provision of flexibility services}

Various technical requirements for EVs providing flexibility services have been derived from the literature review. First of all, since the distribution services are used for voltage and congestion regulation, location of the flexible load has to be defined. It can be listed either as the corresponding connection node or as the superior substation depending on the provided service. For example, [19] reports that exact $\mathrm{EV}$ location is of little importance for transformer congestion control, whereas [6] shows that voltage management services are highly dependent on the point of common connection.

Secondly, additional requirement is the information on active and/or reactive power capabilities, as well as if the EV can provide only unidirectional or bidirectional power flow. Moreover, the size (in $\mathrm{kW}$ ) of available resources is of utter importance. Depending on the given information, the controllers are defined differently as shown in examined literature. Hence, each unit has to provide the DSO or the aggregator with these pieces of information in order for them to know what their flexibility options are.

Even though some literature reports that distributed flexibility resources would be used only few hours in the year [4], others show that they could be valuable asset whenever connected to the grid [24]. Therefore, estimating the frequency of activation during the contracting period is necessary. Moreover, the way the service is activated should be clearly defined since there are diverse possibilities, e.g. direct load control [20] or price-based control [7].

In addition to mentioned pre-requisitions, several other points have been identified within projects dealing with flexibility markets and flexibility products for the distribution grid. Fig. 1 presents the technical requirements recognized for flexibility services in the Nikola project mapped to the requirements defined in three selected projects: iPower project [14], ADDRESS project [25] and VDE RegioFlex project [26]. These projects focus respectively on: developing a platform for SmartGrid flexibility products, enabling the active participation of small consumers in the power system markets, and establishing a regional flexibility market for using regional flexibility options by different DSOs; whereas Nikola project aims at, among others, demonstrating that EVs can provide distribution grid services [27].

Technical requirements shown in Fig. 1 have been recognized as the crucial aspects which must be defined when contracting a flexibility product. It can be seen that most of them have been recognized in all observed projects, e.g. the activation frequency defines how many times can a service be activated within the contracting period, the size $(\mathrm{kW})$ defines the maximal power which can be requested

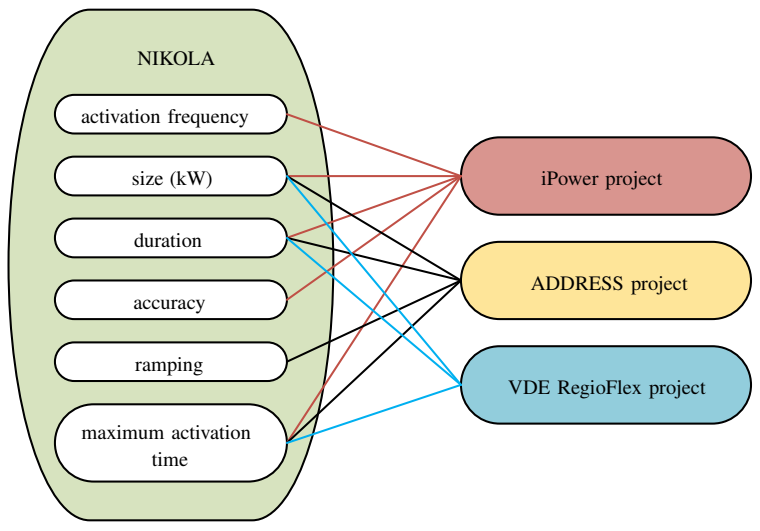

Fig. 1. Technical requirements recognized for DSO flexibility services.

from the flexible load and the duration defines the period within which the service must be active. iPower project also defines the size $(\mathrm{kWh})$ as the maximum energy which can be requested in the contracting period. However, other projects do not recognize this requirement as a crucial one since it is implicitly contained in the power size and the duration. Maximum allowed activation time, ramping and accuracy are considered to be part of the quality of service. In addition to the mentioned requirements, iPower also defines the accuracy as maximum allowed deviations in duration, activation time and size as well as acceptable number of unsuccessful activations.

\section{B. Economic requirements for efficient provision of flexibility services}

Flexibility provision by EVs can provide valuable benefits, such as limiting the need for infrastructure reinforcement, enhancing the congestion management process by direct (V2G) or indirect means (load shifting), and providing voltage management. Nevertheless, in order to activate these resources, some market design adaptations are required.

Firstly, all services provided by the DSOs should be remunerated and/or incentivized. With this transparency effort, economic calculations can be performed to compare the efficiency of choosing between "fit and forget" and "proactive solutions" to solve each DSO task. The regulator must challenge the investment plans of any DSO. It should ask for minimum two scenarios, the "fit and forget" and a "proactive one with the appropriate contractual arrangement to finance it". The authors think that DSOs should have the burden of proving that not managing flexible resources is socially cost-efficient. At minimum, a cost-benefit analysis would be required in order to explain under which conditions the "fit and forget" approach saves public funding compared to "proactive management". Such regulation could encourage DSOs to develop active demand management programs since they would be held responsible for improving their grid management efficiency.

Secondly, definition of clear DSO roles and responsibilities is needed for the implementation of proactive distribution system. Reference [28] describes the existing DSO roles 
including network planning and operation, grid reinforcing and maintaining smart metering infrastructure, and introduces a new role called Distribution Constraints Market Operator which covers contracting and activating flexibilities at different time frames. Flexibility service contracting can be either on bilateral or market basis. The authors believe that an open flexibility platform is needed since individually negotiated bilateral contracts imply transaction costs. This platform would enable to trade several flexibility products through different markets, with their own rules and requirements, and could improve the TSO-DSO cooperation as explained later on. However, if DSOs made an over-investment permitted by the Cost of Service regulation, the value of flexibility would be totally destroyed leading to no need for flexibility market. Hence, regulations have to be carefully formulated to stimulate DSOs in proactive grid management and not to induce unnecessary reinforcement costs.

Further on, the main facilitator for enabling DSO flexibility is the roll-out of smart meters which would allow net metering and is seen as the first step to contracting flexibility services. Currently, the penetration of smart meters varies from country to country, e.g. around $95 \%$ in Italy but only $1.6 \%$ in Germany [29] where the roll-out is not expected in the near future due to their negative cost-benefit analysis. Nevertheless, overall increased penetration is expected at the European level [30]. All installed smart meters have to be certified by the DSO or an independent third party to ensure that they are compatible with the Measuring Instruments Directive. For efficient flexibility provision, the smart meter sampling rate has to be chosen as a trade-off between the need for accuracy and information speed on the one hand, and related metering and data management costs on the other hand. In any case, the rate should not be larger than the market settlement period in which the electricity price does not change. Reference [31] suggests a 5 minutes resolution as a trade-off between the complexity and system performance. The authors believe that a maximum 5 minutes settlement period should be implemented for successful integration of EVs. This is seen as the psychological limit when the users are still willing to wait while their car is providing flexibility services. We assume that everything above 5 minutes would be unacceptable for the user considering that most of the users expect their battery to be fully charged in less than two hours [32]. In addition, many users have even greater expectations, so in average $45 \%$ of them expects the EV to be charged in less than an hour and around $23 \%$ in less than 30 minutes. If the EVs were to provide flexibility services for the transmission system operator as well, the sampling rate should be higher considering that frequency regulation is on second basis. This is not seen as a necessity from the DSO perspective, but can be of additional value.

Another barrier for the participation of small-scale prosumers in the present market structure is the minimum bid size which depends on the provided ancillary service. As an example, minimum capacity for primary frequency reserve in
Denmark is 0.3 MW which is, to the authors' knowledge, one of the lowest required bids in all currently existing markets. However, this minimum bid is still considered to be too high for distribution flexibility services as it is seen that even one EV can be a valuable flexibility asset. Therefore, the minimum capacity should be as minimum as possible to enable demand-response participation in the market, whereas some literature even proposes bidless markets [31] where anybody can respond to the real-time price signals at any time.

Finally, defining the priority between TSO and DSO is of crucial value since providing distribution grid services could trigger the need for system-wide services. Therefore, TSOs and DSOs need to cooperate and exchange information in the proactive grid management [33]. There are two possible ways to improve the relationship between TSOs and DSOs: through cooperation or coordination. The former one implies mutual agreements between the DSOs and TSOs for all the use cases that would require a strong information exchange between the two stakeholders; for instance, such agreements could define priorities for one over the other depending on the considered use case. It is also possible to have a third party (e.g. the regulator) deciding on these agreements. The later one relies on the flexibility platform previously mentioned. If market design is properly addressed, trading flexibility products on this platform could induce a smooth coordination between the different products. In this case, the flexibility providers, e.g. aggregators, could naturally bear the function of coordinators (for instance, if they loose money when making several counter-effective offers, they will enhance coordination inherently). Information exchange via the platform would also allow network operators to act in coordinated manner and re-dispatch flexibility resources if needed.

\section{CONCLUSION}

In this paper, the way DSOs have been operating their grids in the past was first reminded. Because very few loads used to be flexible, and due to their remuneration scheme structure, DSOs had better investing in grid reinforcement costs rather than in implementing active demand management strategies. However, considering the policy and technology changes, the paradigm may evolve. This is especially expected considering that some loads, in particular Electric Vehicles, could turn out to be very efficient flexibility providing units, as it was demonstrated in this work through a literature survey.

Market design recommendations were provided both from a technical and a policy perspective in order to set efficient frameworks for the provision and utilization of flexibility products. The main technical requirements recognized for flexibility products are the activation frequency, size in $\mathrm{kW}$, duration, geographical location and quality of service which includes maximum allowed time, ramping and allowed deviations. In addition, it should be defined if the service is provided by active and/or reactive power modulation as well as if the flexibility provider is unidirectional or bidirectional. 
Several non-technical recommendations have been made as well. First of all, adequate regulation is needed to remunerate DSO services and challenge the investment plans. This would enable easy economic comparison of "fit and forget" approach to "proactive solutions". Secondly, a new DSO role which includes contracting flexibility services needs to be established. Furthermore, the authors believe that contracting the services should be market based with an open flexibility platform which provides transparency for all involved actors. This way TSO would have insights on the flexibility market and could request deactivation of a DSO service if it inadequately interacts with TSO needs. Finally, smart meter roll-out is seen as a main facilitator for enabling distribution flexibility. The smart meter sampling time must not be less than the market settlement period which should be, in authors' opinion, maximum 5 minutes for successful provision of flexibility services by EVs. This would not impose high inconvenience for the user since the EV would be unavailable for the settlement period when it is providing flexibility services.

The future work includes calculating the potential value of flexibility services in Danish low-voltage network. The analysis of flexibility value will be based on real historical data in order to estimate the cost of grid reinforcement which can be postponed when using flexibility services.

\section{ACKNOWLEDGMENTS}

Katarina Knezović is a $\mathrm{PhD}$ student supported by the Danish Research Project "NIKOLA - Intelligent Electric Vehicle Integration" under ForskEL kontrakt nr. 2013-1-12088. More information at www.nikolaproject.info.

Paul Codani is a PhD student who benefits from the support of the Chair "PSA Peugeot Citroen Automobile: Hybrid technologies and Economy of Electromobility", so-called Armand Peugeot Chair led by CentraleSupelec, and ESSEC Business School and sponsored by PEUGEOT CITROEN Automobile.

\section{REFERENCES}

[1] EvolvDSO, "D1.2: Evaluation of current market architectures and regulatory frameworks and the role of DSOs," Tech. Rep., 2014.

[2] Green eMotion, "D4.3 - B2: Grid Impact studies of electric vehicles ; Reinforcement Costs in Low-voltage Grids," Tech. Rep., 2013.

[3] L. Pieltain Fernandez, T. Gomez San Roman, R. Cossent, C. Mateo Domingo, and P. Frias, "Assessment of the impact of plug-in electric vehicles on distribution networks," IEEE Transactions on Power Systems, vol. 26, no. 1, pp. 206-213, Feb. 2011.

[4] B. Biegel, P. B. Andersen, J. Stoustrup, K. S. Rasmussen, L. H. Hansen, S. Ostberg, P. Cajar, and H. Knudsen, "The value of flexibility in the distribution grid," in IEEE PES Innovative Smart Grid Technologies, Europe, Oct. 2014.

[5] L. Carradore and R. Turri, "Electric vehicles participation in distribution network voltage regulation," in Universities Power Engineering Conference (UPEC), 2010 45th International, Aug 2010.

[6] K. Knezović, M. Marinelli, R. Møller, P. Andersen, C. Træholt, and F. Sossan, "Analysis of voltage support by electric vehicles and photovoltaic in a real Danish low voltage network," in Power Engineering Conference (UPEC), 2014 49th International Universities, Sept 2014.

[7] J. Hu, A. Saleem, S. You, L. Nordström, M. Lind, and J. Østergaard, “A multi-agent system for distribution grid congestion management with electric vehicles," Engineering Applications of Artificial Intelligence, vol. 38, pp. 45-58, Feb. 2015.
[8] N. S. Pearre, W. Kempton, R. L. Guensler, and V. V. Elango, "Electric vehicles: How much range is required for a day's driving?" Transportation Research Part C: Emerging Technologies, vol. 19, no. 6, pp. 1171-1184, 2011.

[9] ENTSOE, "Demand side response discussion paper," 2014

[10] European-Commission, "Incorporing demand side flexibility, in particular demand response, in electricity markets," Tech. Rep., 2013.

[11] P. Codani, M. Petit, and Y. Perez, "Diversity of transmission system operators for grid integrated vehicles," in 11th International Conference on the European Energy Market (EEM14). IEEE, May 2014.

[12] Council of European Energy Regulators, "Status review on the transposition of unbundling requirements for DSOs and closed distribution system operators," Tech. Rep. April, 2013.

[13] Union of the Electricity Industry Eurelectric, "Power distribution in Europe," Tech. Rep., 2013.

[14] N. C. Nordentoft, Y. Ding, L. H. Hansen, P. Dybdal Cajar, P. Brath, H. W. Bindner, and C. Zhang, "Development of a DSO-market on flexibility services," Tech. Rep., 2013.

[15] T. Short, "Voltage regulation," in Electric power distribution handbook CRC Press, 2014, ch. 6.

[16] H. Markiewicz and A. Klajn, "Voltage disturbances standard EN50160," Tech. Rep., 2004.

[17] Deutsche Energie-Agentur GmbH, "Ausbau- und Innovationsbedarf der stromverteilnetze in Deutschland bis 2030." Tech. Rep., 2012.

[18] I. Perez-Arriaga, S. Ruester, S. Scwenen, C. Batlle, and J.-m. Glachant, "From distribution networks to smart distribution systems: Rethinking the regulation of European electricity DSOs," Think project - Florence School of Regulation, Tech. Rep., 2013.

[19] X. L. Dang, P. Codani, and M. Petit, "An approach to optimize energy usage of an eco-district by using a smart charging regime of EVs," in PowerTech, 2015 IEEE Eindhoven, 2015.

[20] M. A. López, S. Martín, J. A. Aguado, and S. de la Torre, "V2G strategies for congestion management in microgrids with high penetration of electric vehicles," Electric Power Systems Research, vol. 104, pp. 28-34, 2013.

[21] O. Beaude, Y. He, and M. Hennebel, "Introducing decentralized EV charging coordination for the voltage regulation," in ISGT Copenhagen 2013, Oct. 2013

[22] K. Clement-Nyns, E. Haesen, and J. Driesen, "The impact of vehicle-to-grid on the distribution grid," Electric Power Systems Research, vol. 81, no. 1, pp. 185-192, Jan. 2011.

[23] N. Leemput, F. Geth, J. Van Roy, A. Delnooz, J. Buscher, and J. Driesen, "Impact of electric vehicle on-board single-phase charging strategies on a Flemish residential grid," IEEE Transactions on Smart Grid, vol. 5, no. 4, pp. 1815-1822, Jul. 2014.

[24] K. Knezović, M. Marinelli, P. B. Andersen, and C. Træholt, "Concurrent provision of frequency regulation and overvoltage support by electric vehicles in a real Danish low voltage network," in Electric Vehicle Conference (IEVC), 2014 IEEE International, Dec 2014.

[25] R. Belhomme and Et Al., "D1.1: ADDRESS technical and commercial conceptual architectures," Tech. Rep., 2009.

[26] VDE, "- Regional Flexibility Markets - Using market based flexibility for integration of power from renewables in distribution grids," 2015.

[27] P. B. Andersen, M. Marinelli, O. J. Olesen, C. A. Andersen, G. Poilasne, B. Christensen, and O. Alm, "The Nikola project Intelligent electric vehicle integration," in IEEE PES Innovative Smart Grid Technologies, Europe, Oct. 2014

[28] EvolvDSO, "D1.3 - Preliminary assessment of the future roles of DSOs, future market architectures and regulatory frameworks for network integration of DRES," Tech. Rep., 2014.

[29] Sentec, "The European market for smart electricity meters," Tech. Rep., 2011.

[30] Telefónica Digital, “The smart meter revolution,” Tech. Rep., 2014.

[31] Y. Ding, S. Pineda, P. Nyeng, J. Østergaard, E. M. Larsen, and Q. Wu, "Real-time market concept architecture for EcoGrid EU - A prototype for European smart grids," IEEE Transactions on Smart Grid, vol. 4, no. 4, pp. 2006-2016, 2013.

[32] Deloitte, "Unplugged: Electric vehicle realities versus consumer expectations," Tech. Rep., 2011.

[33] A. Zegers and H. Brunner, "TSO-DSO interaction: An Overview of current interaction between transmission and distribution system operators and an assessment of their cooperation in Smart Grids," Tech. Rep. September, 2014 